\title{
Virtual placements for informatics students in open source business across Europe
}

\author{
Francisco J. García-Peñalvo, Juan Cruz-Benito \\ GRIAL Research Group, Department of Computers and \\ Automatics, Research Institute for Educational Sciences \\ (IUCE) \\ University of Salamanca \\ Salamanca, Spain \\ \{fgarcia,juancb\}@usal.es
}

\author{
Miguel Á. Conde \\ Department of Mechanical, Computer Science and \\ Aerospace Engineering \\ University of León \\ León, Spain \\ mcong@unileon.es
}

\author{
Dai Griffiths \\ Bolton University \\ Bolton, United Kingdom \\ dai.griffiths.1@gmail.com
}

\begin{abstract}
VALS (Virtual Alliances for Learning Society) European Project has the aim of establishing sustainable processes to build knowledge partnerships between Higher Education and companies to collaborate on resolving authentic business problems through open innovation mediated by the use of Open Source Software. To achieve this, VALS builds knowledge partnerships between Higher Education and companies who work together on resolving authentic business problems through open innovation. The innovative approach is to leverage virtual placements of informatics students in companies in order to foster entrepreneurial skills and attitudes, and to make use of the results to establish new learning and teaching methods. This results in the Semester of Code initiative, a set of methods and processes for creating and managing a real virtual placement, and for integrating this into innovative teaching and learning strategy. To show these methods and processes, this paper describes the general methodology designed to perform the Semester of Code, as well as several guidelines on how to develop the software that will support this process. Also describes a real adaptation of theoretical approach of this whole process in the case of an Academic Institution, including comprehensively all the issues affecting the process implementation in a real context.
\end{abstract}

Keywords-Virtual placements, Higher Education, Business, Open Source Software, Semester of Code

\section{INTRODUCTION}

VALS (Virtual Alliances for Learning Society) European Project (40054-LLP-L-2013-1-ES-ERASMUS-EKA) has the aim of establishing sustainable processes to build knowledge partnerships between Higher Education (HE) and companies to collaborate on resolving authentic business problems through open innovation mediated by the use of Open Source Software (OSS), which provide the means whereby HE, students and business can all collaborate to resolve real problems. Not only OSS provides the necessary shared infrastructure and collaborative practice, the companies that manage the software are also hubs, which channel the operational challenges of their users through to the people who can solve them. This has great potential for enabling students and supervisors to collaborate in resolving the problems of businesses, but is constrained by the lack of support for managing and promoting collaboration across the two sectors. The motivation behind the VALS project has its origin in a shared need, to forge greatly improved links between HE students and their teachers, and on the other hand the businesses where those students will find employment. Large sector of the European economy are now mediated by online interactions within a single company, and in the collaboration between organizations. Nevertheless, mobility of students in placements and internships in companies relies on the local connections, which HE have developed, and the location of placements is restricted by the high costs of relocation and living expenses at any significant distance from the home institution. The solution is to create virtual placements [1]. These will make use of the technology that drives the professional environment to organize and carry out placements. The reason this potential has not been fully exploited is that virtual placements have not to date offered experience of an authentic business environment and business problems. Thus, for the approach to be successful, these aspects need to be replicated in a virtual placement. To achieve this, VALS builds knowledge partnerships between HE and companies who work together on resolving authentic business problems through open innovation [2-4]. The innovative approach is to leverage virtual placements of informatics students in companies in order to foster entrepreneurial skills and attitudes, and to make use of the results to establish new learning and teaching methods. This result in a Semester of Code methodology, a sustainable set of methods and processes for creating and managing virtual placements, and for integrating these into innovative teaching and learning strategies.

The VALS focus is, on the one hand, real world business problems, and on the other, education that involves programming. These may be from a wide variety of areas of study, not only ICT. This is a promising area for establishing industrial/educational collaboration, because there is: a) Established practice of external participation in business, in which software artifacts are developed outside a business, and then applied within it [5-7] and b) A very wide range of real 
world business problems can be addressed. Within this context, Open Source Software (OSS) [8] will be used as an enabling technology. This has a number of significant advantages, but nevertheless, the VALS method is extensible to any innovation that is mediated by software, so long as the legal and organizational barriers created by licensing terms can be overcome. OSS provides the means whereby HE institutions, students, businesses and foundations can all collaborate to resolve authentic business problems. Firstly, OSS provides the necessary shared infrastructure: it is accessible to students, and businesses are not constrained by intellectual property or commercial interests, which prevent them engaging with educational placements. Secondly, OSS provides a context of well-established collaborative practice within which authentic business tasks are shared remotely, and beyond the confines of an individual organization. Moreover, the foundations that manage the software are also hubs, which channel the operational challenges of their users through to the people who can solve them. This has great potential for enabling students and supervisors to collaborate in resolving the problems of businesses, but is constrained by the lack of support for managing and promoting collaboration across the two sectors. Thus, VALS will provide the methods, practice, documentation and infrastructure to unlock this potential through virtual placements in businesses and other public and private bodies, and the pilots, promoting these as the "Semester of Code" [9].

This paper is organized as follows (apart this first introductory section): the second section (How to run Semester of Code) describes how will be performed the actions and initiatives posed in the Project (mainly the Semester of Code), the third section (Case Study: VALS and The University of Salamanca) explains a real case study in which an academic institution (the University of Salamanca, Spain for example) could adapt project ideas to its real context. To complete the paper there is a fourth section with the overall conclusions of the explained ideas, and some future work.

\section{HOW TO RUN SEMESTER OF CODE}

As explained previously, The Semester of Code (SoC) is an initiative of the European VALS project, which allows students of degrees of computer science addressing real business problems raised by companies and OSS Foundations, and get rewards from resolving them reflecting it in their formal education. This initiative consists of two action lines, one on managing the entire process of Semester code, and another on the computer system that will support the achievement of this initiative with all stakeholders. The following subsections describe how VALS project conducted these action lines, and what key issues are given in each.

\section{A. Managing the Semester of Code Initiative}

To carry out the process of the Semester of Code, it is necessary to include various stakeholders who have several key characteristics inherent in each, among them the following: Academic Institutions: they provide the students and Academic Mentors necessary for the consecution of Projects posed in the Semester of Code. It is possible to have two types of Institutions, those directly related to the project, and others that are not, but can go incorporating over the course of the initiative. The Academic Institutions associated with the project from the beginning, must adapt and test the workflow of the Semester of Code, disseminating the initiative and results later. Thus, those Academic Institutions not related to the initiative at the beginning can be incorporated along the same and grow the proposed process. The Companies and Foundations: for this Project, the companies have been included in the development team from the beginning. This has ensured that the conditions and designed work flows can adapt the operation of a real company. In addition, all companies included in the project team are related to the field of Open Source Software, so which already have the knowledge in this fields, and relationships with other companies with the same scope from the beginning of the project. This knowledge and relationships make these members of the development team of the project be able to attract foundations and other companies related to the development and promotion of free software, so that they can be incorporated into the Code of Semester Initiative, proposing projects and accepting temporally students in their development teams.

The process itself to carry out the Semester of code could be summarized as follows: the Academic Institutions adapt the Semester of Code workflow and ensure their own bureaucratic issues for the next edition of the Semester of Code. Also they seek for students interested in this kind of practices, in order to know the audience that they may have in the project applications. Based on the estimated audience, the Companies involved in the project and stakeholders related to the Open Source Software seek Foundations and Companies interested in delivering projects and tasks to be resolved by students. This interest may cover both the solution for the task and the search for talent in students, which can be incorporated after in a professional way in those Foundations or Companies. The managers of the Semester of Code compile and approve (or reject) the projects proposed by Companies or Foundations. These projects should fit a temporary extension of work up to 3 months, must be suitable to be solved by students of careers related to Computer Science, and should be real business problems or unresolved tasks of the Company or Foundation (to train the student in the real work context, not as usually in the academic context). The students apply for the projects who are interested, including in the proposal an Academic Mentor who have agreed with the student proposal. The Companies or Foundations select the students and solutions to solve the tasks and projects proposed, and agree with the students and Academic Institutions the details of the deliverables, etc. The students develop the projects and submit them to the Companies and Foundations, the Companies and Foundations assess the work done by the students and finally, the Academic Mentors assess also the work done by the student and fix the academics rewards for the student with their Academic Institution.

The following subsection will explain the internal workflow of the Virtual Placement System developed to support the Semester of Code process.

\section{B. Semester of Code Virtual Placement System}

To support the online part of the process for Semester of Code, VALS project team is developing the Virtual Placement System by adapting a Drupal platform [10], so that it can 
withstand the flow of necessary communication between the different stakeholders involved in the initiative. Other proposals attempt to make similar initiatives such as the Google Summer of Code [11], opt for platforms developed ad hoc for these cases, as for example, Melange [12]. For the Semester of Code, it was decided to use a well known system as Drupal, achieving a simpler development and ensuring easier improvement processes and maintenance in the future. Following the scope of this VALS project, this development will be public and under Open Software licenses for use by other communities interested in goals such as this project.

\section{CASE STUDY: VALS AND THE UNIVERSITY OF SALAMANCA}

In each real case adaptation of the VALS goals and initiatives, it is capital to define correctly the staff involved in each institution, the bureaucratic issues that could appear, the possible academic rewards that will be apply to students, and how the worldflow of the Project itself and the workflow of the Semester of Code initiative could be adapted to perform properly the whole solution designed by researchers, taking into account the weaknesses and strengths of each institution and thinking about how to deal with them. In this section will be explained how one Academic Institution (the University of Salamanca, Spain), has designed the adaptation from the theoretical design of the Semester of Code to a real case application. In this adaptation, the different issues and challenges peculiars of this University have been facing up. These could be resumed in the following terms:

The teams involved to run the Semester of Code at the University of Salamanca are: GRIAL Research Group [13]: coordinators of the VALS project and staff from this University. This group will coordinate also the workflow and project diffusion in the University. Service of Professional Insertion, Practices and Employment (SIPPE): this service ensures the bureaucracy related to the professional practices of all students in the University. Its staff will help in formal questions and in agreements signing between students and the Companies and Foundations involved in Semester of Code. Faculty of Sciences: it is the Faculty where the students of Computer Science belong at the University. It establishes regulations, formal procedures and timeframes for the completion of internships and other academic issues relevant for the project. Department of Computers and Automatics: the informatics teachers and other technical staff belong to this Department. These become the academic mentors or supervisors for the students involved in the Semester of Code.

The Academic Rewards planned in this University for the Students are: possible adaptation of work done in Semester of Code for students' Master Thesis or Degree Thesis, achieving of curricular practices in Informatics Engineering Degree and Master (MsC) in Informatics Engineering. Official recognition of hours and work done in the Semester of Code awarded in credits, achieving of non-curricular practices (which are not mandatory in Computers Engineering in this University). The official recognition of hours and work done in Semester of Code through a certificate.

On the other hand, the timeframe accorded for this university to run the Semester of Code process and the Virtual
Placement in the companies and foundations is: Between March and June of previous academic season of completion of curricular practices, the students must notify to the University (SIPPE and Faculty of Sciences) their intention to make professional practices (through Semester of Code or the usual way in the University). Between September and October of the academic season (at the beginning of this), the student may decide to participate in the Semester of Code. The decision depends of the projects and proposals posed in the Semester of Code Virtual Platform, the student may apply for these they want. When they decide it, they should to contact with professors of the Department of Computers and Automatics to get feedback from them. Usually they will do that with teachers related to the areas near to project proposals which students want. If these contacts are successful, the professor will help the student to pose a solution for the problem and to apply for the project proposal, becoming the Academic Supervisor or Academic Mentor of the Student in the Semester of Code. In this feedback process, the students would discuss their ideas with other students and teachers individually, or if the professors consider it positive, they could organize some meetings open to students interested in Semester of Code to help them in this phase. In October the students make their application into the Semester of Code Virtual Platform to resolve the projects they are interested. In this application process, they will provide their approach to solve the problem, they will pose an Academic Supervisor, and other questions that each Foundation or Company arise in the proposal (Grade Point Average - GPA, Curriculum Vitae, etc.). In November, each Foundation or Company involved in the Semester of Code will publish the student who is selected to solve the problem proposed. These Foundations or Companies will contact with the student (and even with the Academic Mentor designated). At this moment will be established a three-way communication, between the student, the University (represented by the Academic Mentor and SIPPE) and the Company or Foundation, in order to agree on the details and conditions of the project and sign the agreement needed. In this phase, the Company or Foundation will designate a Mentor for the student (who will communicate and help the student to resolve the project proposed). The sign of agreement would be before December endding. If the student does not been accepted for any project, he or she should notify it to the SIPPE and Faculty of Sciences, in order to get professional practices in the habitual way, with local or national software companies or foundations. Also, when the student knows if is accepted to solve any project, he or she could request to Department of Computers and Automatics the use and adaptation of the work that will do in Semester of Code for the Final Master Thesis or Final Degree Thesis. Between January and June the students will develop the approach posed for the project. These dates are estimated, thus these need to be fixed almost between student and Company or Foundation. This timeframe is the best for the students' academic season in last course of the Master (MsC) or Degree, so it is the recommended in the academic calendar (less subjects and hours of lectures). In these months, students and Company Mentors can fix another requirements of the Project (deliverables, etc.). Finally, the students will deliver the project to the Company or Foundation, which will give feedback of the process to the academic institution. Besides 
this feedback from the business part, the Academic Mentor will give its own feedback, more focused on the educational and formal part of the project. Based on these two reports of the work done, the Academic Institution can rewards the student with certificates, completion of credits, allowing to deliver the Final Master Thesis or Final Degree Thesis based on the work done in Semester of Code, etc. This whole process is summarized schematically in the figure 1 .

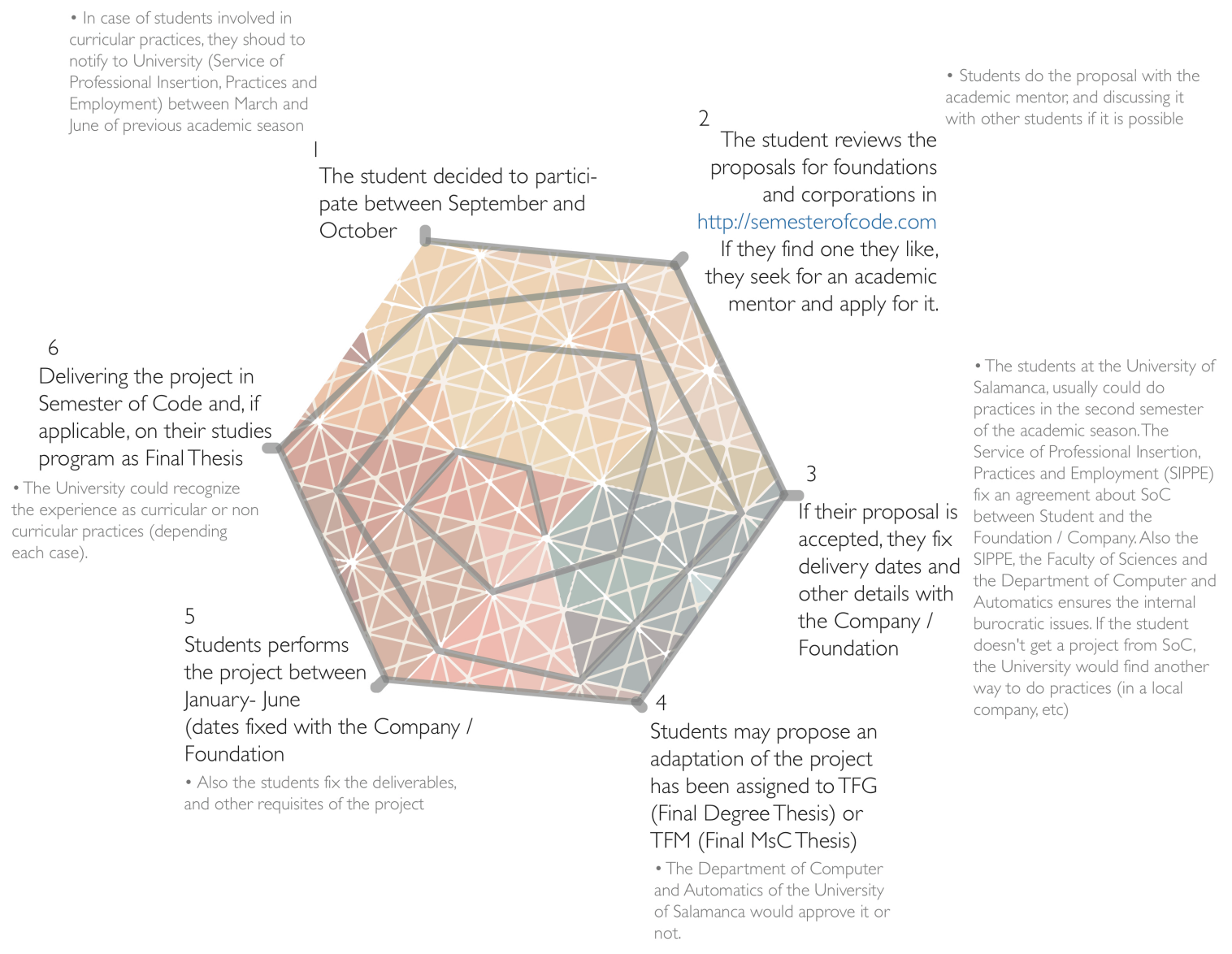

Figure 1: Lifecycle of Semester of Code adapted to the University of Salamanca case

\section{CONCLUSIONS}

We believe that collaboration on open source development between universities, companies and foundations is a way to achieve all VALS goals in a "win-win" fashion, and long-term alliances. The innovation in the Virtual Placement Systems is also part of this "win-win" strategy adopted for VALS project, because it allows both Companies and Foundations and students have opportunities which they have not usually available in the context of the practices. On the one hand, allows Companies and Foundations have a much larger audience to solve their business problems or to find talent among Higher Education students effectively. On the other hand, the innovation in the Virtual Placement System allows students to access opportunities in Companies and Foundations that could not otherwise because their physical location, allowing to save costs derived from the stay and life in other countries, so it allows to open a wide range of opportunities for students also regardless economic or social situation of them. The methodology and guidelines provided by VALS must enhance the effectiveness of all partners operations, and provide a means of transforming significant sectors of educational and industrial activity. In this regard, is so important in the first six months of the project to have a detailed theoretical approach of the collaboration flowchart between stakeholders, and to have an effective adaptation to the real context in Academic Institutions, as this will allow the researchers team to develop in a better way the software that will support the whole process.

\section{ACKNOWLEDGMENT}

With the support of the Lifelong Learning Program of the European Union. Project Reference: 540054-LLP-1-2013-1ES-ERASMUS-EKA. This project has been funded with support from the European Commission. This publication only reflects the views of the authors, and the Commission cannot be held responsible for any use which may be made of the information contained therein. 


\section{REFERENCES}

[1] Vriens, M., et al. Virtual placements: Improving the international work experience of students. in EDULearn10, International Conference on Education and New Learning Technologies. 2010. Barcelona (Spain), 57 July 2010.

[2] García-Peñalvo, F.J., C. García de Figuerola, and J.A. Merlo, Open knowledge management in higher education. Online Information Review, 2010. 34(4): p. 517-519.

[3] García-Peñalvo, F.J., C. García de Figuerola, and J.A. Merlo, Open knowledge: Challenges and facts. Online Information Review, 2010. 34(4): p. 520-539.

[4] Chesbrough, H.W., Open Innovation: The new imperative for creating and profiting from technology. 2003, Boston: Harvard Business School Press.

[5] van Dorp, C.A., ed. Stimulating Employability through Cross Sector Virtual Mobility. European funded research on flexible modality internships. 2008, European Association of Distance Teaching Universities: The Netherlands.

[6] Op de Beeck, I., M. Vriens, and W. van Petegem. Enhancing international work placements through virtual mobility: The EU-VIP project. in 18th EDINEB Conference 'From innovation to crème de la crème education'. 2011. June 7-10, 2011, IDRAC, Lyon, France.

[7] Rintala, U., State-of-the-art in support of virtual placements. A study carried out in the framework of the EU - VIP project. 2009.
[8] European Commission, Strategy for internal use of OSS at the EC. 2013, European Commission.

[9] García Peñalvo, F.J, Álvarez Navia, I., García Bermejo, J.R., Conde González, M. A., García-Holgado, A., Zangrando, V., Seoane Pardo, A. M., Cruz-Benito, J., Lee, S., Elferink, R., Veenendaal, E., Zondergeld, S. Griffiths, D., Sharples, P., Sherlock, D., De Toni, A., F. Battistella, C., Tonizza, G., De Zan, G., Papadopoulos, G. A., Kapitsaki, G. Achilleos, A. P., Mettouris, C., Cheung, S., Guerrero, Z., He, E., Alier Forment, M., Mayol, E., Casany, M. J., Wilson, S., Wilson, R. and Johnson, M., VALS: Virtual Alliances for Learning Society. 2013. In TEEM Conference 2013. Technological Ecosystems for Enhancing Multiculturality, 14-16 November, 2013, Salamanca, Spain

[10] Drupal CMS (2014, April 10). About Drupal [Online]. Available: https://drupal.org/about

[11] Google Inc. (2014, April 10). Google Summer of Code [Online]. Available: https://developers.google.com/open-source/soc

[12] Melange (2014, April 10). Melange SoC [Online]. Available: $\mathrm{http}: / /$ code.google.com $/ \mathrm{p} / \mathrm{soc} /$

[13] García-Peñalvo, F. J., Rodríguez-Conde, M. J., Seoane-Pardo, A. M., Conde-González, M. Á., Zangrando, V. and García-Holgado, A., GRIAL (GRupo de investigación en InterAcción y eLearning), USAL, IE Comunicaciones. Revista Iberoamericana de Informática Educativa, pp. 85-94, 2012. 